\title{
Synthesis of ellagic acid glucoside using glucansucrase from Leuconostoc and characterization of this glucoside as a functional neuroprotective agent
}

\author{
Hyejin $\mathrm{Yu}^{1 \dagger}$, Hana Jeong ${ }^{1 \dagger}$, Kwang-Yeol Yang ${ }^{2}$, Jeong-Yong Cho ${ }^{3}$, In Ki Hong ${ }^{4}$ and Seung-Hee Nam ${ }^{1,3^{*}}$
}

\begin{abstract}
Ellagic acid glucoside was synthesized via transglucosylation using sucrose and glucansucrase derived from Leuconostoc mesenteroides B-512 FMCM. After such enzymatic synthesis, the product was purified by $50 \%$ ethyl acetate fraction and C18 column chromatography. Modification of ellagic acid glucoside was verified by LC-MS/MS at $\mathrm{m} / \mathrm{z}$ $485.1(\mathrm{M}+\mathrm{Na})^{-}$and $\mathrm{m} / \mathrm{z} 531.1(\mathrm{M}+3 \mathrm{Na})^{-}$. The yield of ellagic acid glucoside was $69 \%$ (3.47 $\mathrm{mM}$ ) by response surface methodology using $150 \mathrm{mM}$ sucrose, $300 \mathrm{mU} / \mathrm{mL}$ glucansucrase, and $5 \mathrm{mM}$ ellagic acid. The synthesized ellagic acid glucoside showed improved water solubility, up to 58\% higher brain nerve cell (SH-SY5Y) protective effect, threefold higher cortisol reducing effect, and fourfold stronger inhibitory effect on acetylcholinesterase (AChE) than ellagic acid. These results indicate that ellagic acid glucoside could be used as a neuroprotective agent.
\end{abstract}

Keywords: Ellagic acid, Glucansucrase, Leuconostoc mesenteroides, Transglucosylation, Brain protective effect

\section{Introduction}

Ellagic acid is a phenolic compound and also, dilactone dimer form of gallic acid. It is contained in many fruits such as strawberries, blackberries, raspberries, and pomegranates (Yoshimura et al. 2005). Previous studies have shown that ellagic acid can protect brain cells against stress, improve cognitive ability, and prevent Alzheimer's disease (Farbood et al. 2015). Anti-mutagenic, anti-inflammatory, anti-cancer, and antioxidant effects of ellagic acid have also been reported (Priyadarsini et al. 2002). In addition, ingesting pomegranate extract containing $100 \mathrm{mg}$ of ellagic acid per day for 4 weeks could improve skin pigmentation caused by UV rays for human (Kasai et al. 2006).

*Correspondence: namsh1000@hanmail.net; namsh1000@jnu.ac.kr

${ }^{\dagger}$ Hyejin Yu and Hana Jeong contributed equally to this work

${ }^{1}$ Institute of Agricultural Science and Technology, Chonnam National

University, Gwangju 61186, South Korea

Full list of author information is available at the end of the article
Because of these effects, pomegranate extract juice is sold in Korea by promoting that it contains a lot of ellagic acid. However, pharmaceutical and cosmetic applications of ellagic acid are limited due to its extremely low water solubility.

To solve these problems, enzymatic modification of phenolic compounds using transglycosylation enzymes such as glucansucrase has attracted attention because such modifications could improve their physical, chemical, and physiological properties (Moon et al. 2007b). Glucansucrase not only can catalyze the synthesis of dextran from sucrose by transglucosylation, but also can catalyze the transfer of a glucose unit to other carbohydrates or phenolic compounds via glycosidic linkages (Moon et al. 2006; Robyt et al. 2008). Enzymatic transglycosylations by dextransucrase from Leuconostoc mesenteroides have been used to improve bioactivities and functional properties of various compounds (Seo et al. 2009). According to our previous studies, transglycosylated gallic acid shows higher anti-lipid peroxidation and stronger 
inhibition activities against tyrosinse than gallic acid (Nam et al. 2017b). Caffeic acid glucoside shows stronger inhibition on colon cancer cell growth than caffeic acid without transglycosylation (Nam et al. 2017a).

In this study, ellagic acid glucoside was synthesized from sucrose, ellagic acid, and glucansucrase from $L$. mesenteroides B-512 FMCM. The produced ellagic acid glucoside was purified by column chromatography and confirmed by LC-MS/MS. Optimal production conditions for ellagic acid glucoside were determined by response surface methodology. Moreover, functional properties of ellagic acid glucoside were investigated to determine its potential functions as a health supplement, including its antioxidant, brain cell protective, anti-stress, and acetylcholinesterase (AChE) inhibition activities.

\section{Materials and methods Materials}

Ellagic acid, silica gel, sucrose, glucose, maltose, 3-(4,5-dimethylthiazol-2-yl)-2,5-diphenyl-tetrazolium bromide (MTT), and 1,1-diphenyl-2-picrylhydrazyl (DPPH) were purchased from Sigma-Aldrich (St. Louis, MO, USA). All chemical reagents were of analytical grade and purchased from commercial sources.

\section{Enzyme preparation}

Glucansucrase (EC 3.2.1.11) for transglycosylation was obtained from $L$. mesenteroides B-512 FMCM (KCCM $11728 \mathrm{P})$, grown on LM medium with $2 \%(\mathrm{w} / \mathrm{v})$ glucose as previously described (Moon et al. 2007a). Fermented culture was collected, centrifuged, and concentrated using $30 \mathrm{~K}$ hollow fibers (Millipore, Bedford, MA, USA). Its enzyme activity was measured at $28^{\circ} \mathrm{C}$ using $100 \mathrm{mM}$ sucrose as a substrate in $20 \mathrm{mM}$ sodium-acetate buffer ( $\mathrm{pH}$ 5.2) for various reaction time. Reactant aliquots were spotted onto a thin layer chromatography (TLC) silica gel 60 plate (Merck, Darmstadt, Germany) and developed in acetonitrile/water $(85: 15, \mathrm{v} / \mathrm{v})$ solution. The TLC plate could be visualized by dipping into $0.03 \%(\mathrm{w} / \mathrm{v})$ $N$-(1-naphthyl)-ethylenediamine and $5 \%(\mathrm{v} / \mathrm{v}) \mathrm{H}_{2} \mathrm{SO}_{4}$ in methanol followed by heating at $120{ }^{\circ} \mathrm{C}$ for $10 \mathrm{~min}$. The amount of released fructose was measured using an NIH densitometry Image Program (http://rsb.info.nih.gov/ nih-image) with a standard compound. One unit (U) was defined as the amount of enzyme that caused the release of $1 \mu \mathrm{mol}$ of fructose per minute at $28{ }^{\circ} \mathrm{C}$ in $20 \mathrm{mM}$ sodium acetate buffer ( $\mathrm{pH}$ 5.2).

\section{Synthesis, extraction, purification, and identification of ellagic acid glucoside}

The reaction mixture $(250 \mathrm{~mL})$, which consisted of $10 \mathrm{mM}$ ellagic acid, $355 \mathrm{mM}$ sucrose, and B-512 FMCM glucansucrase $(0.65$ units $/ \mathrm{mL})$, was incubated in $20 \mathrm{mM}$ sodium acetate $(\mathrm{pH} 5.2)$ at $28{ }^{\circ} \mathrm{C}$ for $6 \mathrm{~h}$ and boiled for $5 \mathrm{~min}$ to inactivate the enzyme reaction. Glucosylated ellagic acid was confirmed by TLC plate analysis (Merck, Darmstadt, Germany) at room temperature. The reaction mixture was spotted onto a TLC plate and developed with ethyl acetate/acetic acid/water (3:1:1, v/v/v) using ellagic acid, fructose, and sucrose as standard materials. The developed plate was observed at UV $254 \mathrm{~nm}$ and visualized with $0.03 \%$ (w/v) $N$-(1-naphthyl)-ethylenediamine- $\mathrm{H}_{2} \mathrm{SO}_{4}$ solution as described previously in "Enzyme preparation" section.

The reaction mixture was separated with $50 \%$ ethyl acetate to obtain glucosylated ellagic acid from upper layer. The upper layer solution was further concentrated under vacuum using a rotary evaporator (EYELA, Tokyo, Japan) at $47{ }^{\circ} \mathrm{C}$ and re-dissolved in $50 \%$ methanol $(\mathrm{v} / \mathrm{v}$, $50 \mathrm{~mL}$ ). The sample was loaded on the top of a C18 silica gel column $(5.0 \times 50 \mathrm{~cm})$. After removing remaining sugars with distilled water (total of $500 \mathrm{~mL}$; flow rate at $1 \mathrm{~mL} / \mathrm{min}$ ), ellagic acid glucoside was gradually eluted with $10-100 \%(\mathrm{v} / \mathrm{v})$ methanol. The eluted sample solution was further purified by HPLC on a PDA-MD2015 instrument (JASCO, Kyoto, Japan) using the following conditions: $\mu$-Bondapak C18-reverse-phase column $(10 \mu \mathrm{m}, 300 \times 19 \mathrm{~mm}$, Waters, Milford, MA, USA); 0.1\% formic acid in distilled water (mobile phase A) and $0.1 \%$ formic acid in methanol (mobile phase B); flow rate at $0.9 \mathrm{~mL} / \mathrm{min}$; oven temperature at $40{ }^{\circ} \mathrm{C}$; and detection wavelength at $254 \mathrm{~nm}$. Molecular mass and chemical structure of the product were determined with an LC-MS/MS Synapt HDMS system (Waters, Milford, MA, USA) through electrospray ionization tandem mass spectrometry.

\section{Optimization of ellagic acid glucoside production}

The condition of ellagic acid glucoside synthesis was optimized using response surface methodology (RSM). Experimental data were applied via the response surface regression procedure with the second-order polynomial equation as follows (Khuri and Mukhopadhyay 2010): $Y$ $=\beta_{0}+\beta_{1} x_{1}+\beta_{2} x_{2}+\beta_{3} x_{3}+\beta_{11} x_{1}{ }^{2}+\beta_{22} x_{2}{ }^{2}+\beta_{33} x_{3}{ }^{2}+\beta_{12} x$ ${ }_{1} x_{2}+\beta_{13} x_{1} x_{3}+\beta_{23} x_{2} x_{3}$. Statistical analyses of the experimental design were performed using Design Expert 6.0.11 software (SAS Institute Inc., Cary, NC, USA). Fit quality for the model equation was indicated by coefficient of determination $\left(R^{2}\right)$ or adjusted $R^{2}$ representing the fitness of the polynomial model equation. Preliminary experiments were performed to optimize conditions for ellagic acid glucoside production: glucansucrase from L. mesenteroides, 61-1, $239 \mathrm{mU}$; sucrose, 10-700 mM; and ellagic acid, 0.1-25.1 mM. 


\section{Water solubility and antioxidant activity}

In an Eppendorf tube, ellagic acid and ellagic acid glucoside were weighed at concentrations of 1,5 , and $10 \mathrm{mM}$. The precipitate was observed by adding water and sonicating for $1 \mathrm{~h}$. Antioxidant activities of ellagic acid and ellagic acid glucoside were detected using 1-diphenyl-2-picrylhydrazyl (DPPH). Samples containing 0.01-1.0 mM solutions of ellagic acid and ellagic acid glucoside in ethanol were allowed to react with $100 \mathrm{mM}$ $\mathrm{DPPH}$ solution for $10 \mathrm{~min}$ at $25{ }^{\circ} \mathrm{C}$. Absorbance values were then obtained at $517 \mathrm{~nm}$ using a microplate reader (Molecular Devices, Sunnyvale, CA, USA). Radical scavenging activity was expressed as the percentage of inhibited DPPH radical concentration against ascorbic acid as a reference compound. The value of $\mathrm{IC}_{50}$ was designated as the concentration of a compound that resulted in $50 \%$ reduction in DPPH radicals.

\section{Brain cell protective and anti-stress effects}

SH-SY5Y human neuroblastoma cells (KCLB 22266, Korean Cell Line Bank, Seoul, Korea) were used to determine the neuronal protective effect. These cells were cultured in RPMI-1640 medium supplemented with 10\% fetal bovine serum (Sigma-Aldrich, St. Louis, MO, USA) and $1 \%$ antibiotic-antimycotic (Sigma-Aldrich, St. Louis, $\mathrm{MO}$, USA) in a humidified atmosphere with $5 \% \mathrm{CO}_{2}$ at $37^{\circ} \mathrm{C}$. These cells were then plated onto 96-well plates at a density of $10^{4}-10^{6}$ cell $/ \mathrm{mL}$ of medium. After $24 \mathrm{~h}$, they were treated with different concentrations $(1-100 \mu \mathrm{M})$ of ellagic acid and its glucoside. After treatment with $100 \mathrm{mM}$ glutamate, cell viability was measured by MTT assay. As a positive control, 1 and $10 \mu \mathrm{M}$ theanine was used. The absorbance was measured at $570 \mathrm{~nm}$ wavelength to investigate the effect of stress protection based on cell viability.

In order to quantify the anti-stress effect, the supernatant of medium solution was used after centrifugation. The experiment was performed at $4{ }^{\circ} \mathrm{C}$. The anti-stress effect was measured using a Cortisol ELISA Kit (Calbiotech Inc., Los Angeles, CA, USA). Absorbance at $450 \mathrm{~nm}$ was measured using a microplate coated with cortisol MAb (monoclonal antibody).

\section{Acetylcholinesterase (AChE) inhibition activity}

SH-SY5Y cells were treated with $100 \mathrm{mM}$ glutamate to induce stress as previously described. After treatment with ellagic acid and its glucoside at two concentrations $(50$ and $100 \mu \mathrm{M})$, the supernatant of the medium was collected after centrifugation. Anti-dementia effects of ellagic acid and its glucoside were measured based on their inhibition activity on $\mathrm{AChE}$ enzyme known to degrade acetylcholine, a neurotransmitter, using Acetylcholinesterase (AChE) Inhibition Assay Kit (SigmaAldrich, St. Louis, MO, USA).

\section{Statistical analysis}

The data were statistically processed using one-way analysis of variance (ANOVA). The experiments were repeated in triplicate and expressed as mean and standard deviation. Comparison of the difference in values between different groups was done through Duncan's multiple-range test using SPSS program (SPSS version 23.0 for windows, SPSS Inc., Chicago, IL, USA). The data on functional evaluation were assessed using the Student's $t$-test. Values of $p<0.05$ were considered significant.

\section{Results}

Synthesis, purification, and identification

The activity of glucansucrase from $L$. mesenteroids B-12FMCM was $10.5 \mathrm{U} / \mathrm{mg}$ at $28^{\circ} \mathrm{C}$ under condition of $100 \mathrm{mM}$ sucrose as substrate in $20 \mathrm{mM}$ sodium-acetate buffer ( $\mathrm{pH}$ 5.2). Ellagic acid glucoside was obtained from a solution containing $10 \mathrm{mM}$ ellagic acid, $355 \mathrm{mM}$ sucrose, and $0.65 \mathrm{U} / \mathrm{mL}$ glucansucrase. Ellagic acid glucoside was detected as a reaction product of glucansucrase with ellagic acid and sucrose by HPLC (Fig. 1a). The reaction mixture was separated by ethyl acetate partitioning, which removed unreacted hydrolyzed carbohydrates or enzymes present in the lower layer, whereas ellagic acid and ellagic acid glucoside were concentrated in the upper layer. Furthermore, C18 column chromatography was used to purify the products. The column was washed with water to remove remained sugars or enzyme followed by elution with 10-100 (v/v) methanol gradient to obtain products with $50-60 \%$ methanol. The number of glucose units attached to the synthesized products was verified by LC-MS/MS. Molecular ions of ellagic acid glucoside were observed at $\mathrm{m} / \mathrm{z} 485.1(\mathrm{M}+\mathrm{Na})^{-}$and $531.1(\mathrm{M}+3 \mathrm{Na})^{-}$ (Fig. 1b). When a glucose moiety was added to ellagic acid, the molecular weight of the compound was increased to the expected structure via a glycosidic linkage (Fig. 1c). This study revealed that glucansucrase from L. mesenteroides B-512 FMCM could be used to synthesize glycoside linkage for a phenolic compound like other previous experiments (Nam et al. 2017a, b).

\section{Optimum ellagic acid glucoside synthesis}

The effect of three variables (sucrose concentration, glucansucrase unit, and ellagic acid concentration) on the yield of ellagic acid glucoside was determined. A total of 20 experiments were performed to investigate the interaction of these variables to ellagic acid glucoside synthesis. The synthesis of ellagic acid glucoside was 

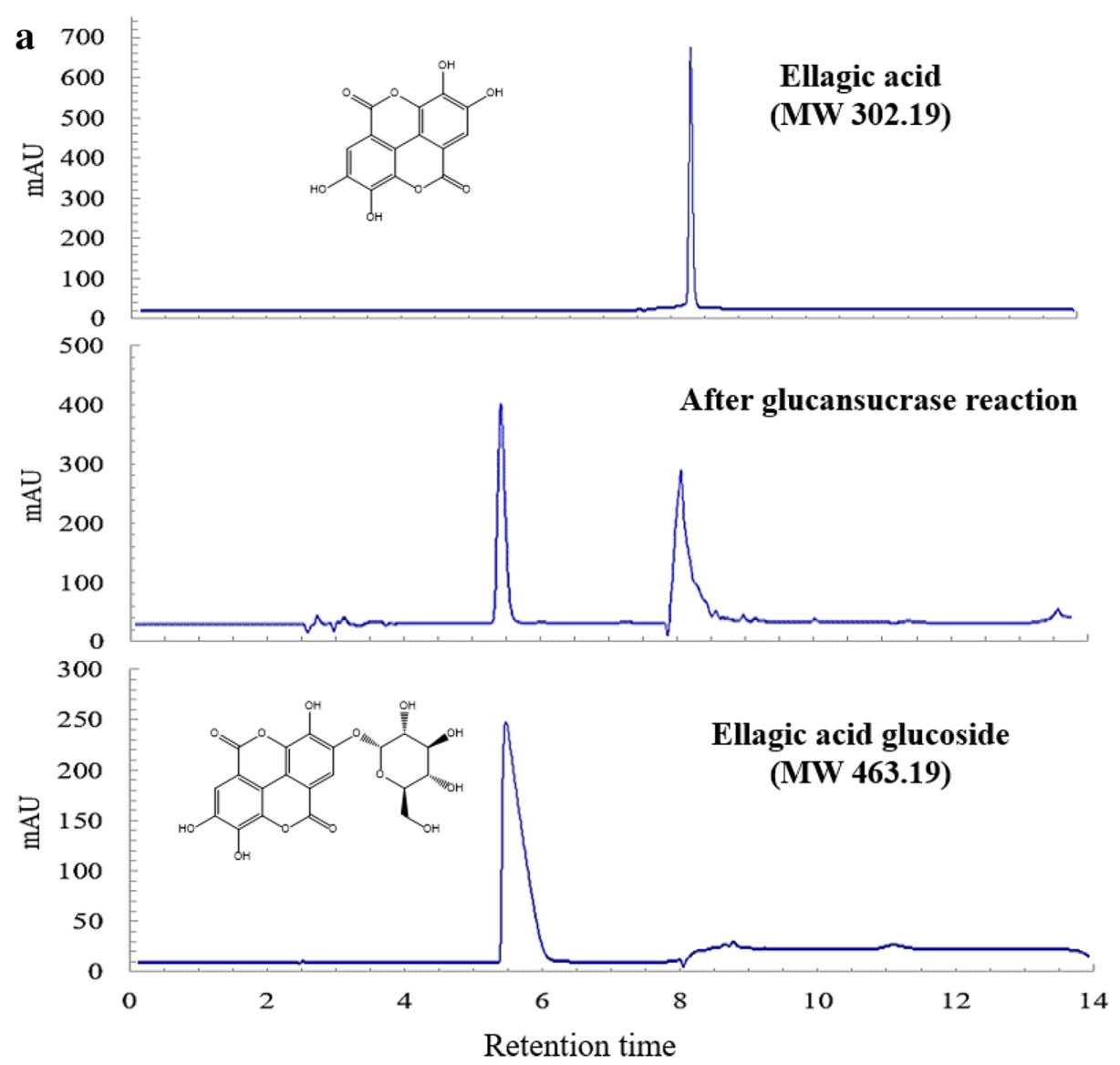

b

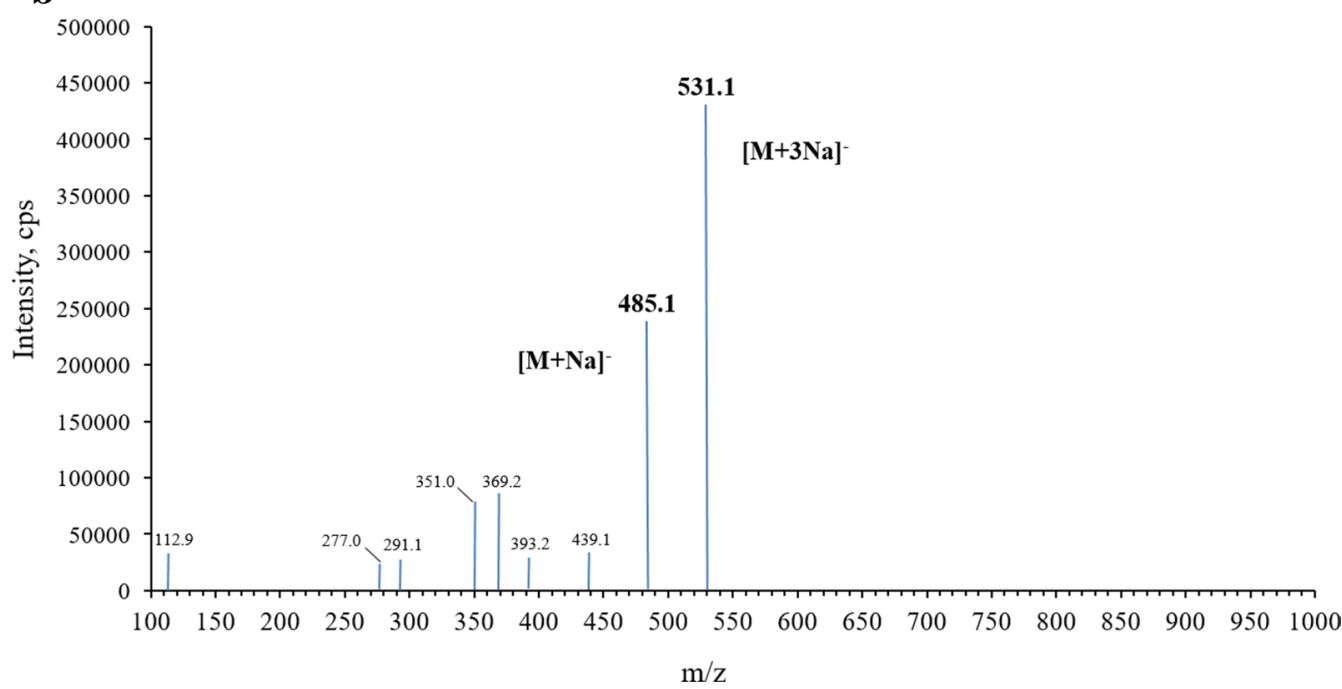

Fig. 1 HPLC chromatogram, mass spectrum, and schematic diagram of the reaction of ellagic acid and ellagic acid glucoside after column chromatography purification. Ellagic acid standard, after the reaction with glucansucrase, and purified ellagic acid glucoside (a), LC-MS/MS spectrum of ellagic acid glucoside (b), and a schematic diagram of the reaction (c) 


\section{c}

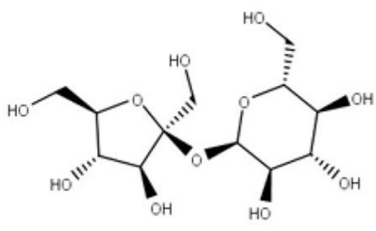

Sucrose

Glucansucrase

from $L$. mesenteroides

$$
+
$$

$28^{\circ} \mathrm{C}, \mathrm{pH} 5.2$

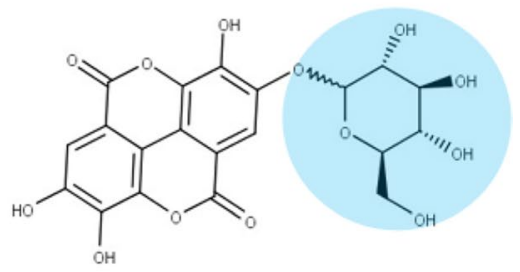<smiles>O=c1oc2c(O)c(O)cc3c(=O)oc4c(O)c(O)cc1c4c23</smiles>

Ellagic acid glucoside

Ellagic acid

Fig. 1 continued

optimized by CCD matrix using actual and predicted values as shown in Table 1. Interactions of these variables were evaluated by RSM within the range from -1.682 to + 1.682 (Additional file 1: Table S1). Ellagic acid synthesis using glucansucrase was expressed with the following regression equation:

$$
\begin{aligned}
\mathrm{Y}= & -4.630+0.011 \mathrm{X}_{1}+0.008 \mathrm{X}_{2}+0.443 \mathrm{X}_{3} \\
& +0.0000004 \mathrm{X}_{1}^{2}-0.000008 \mathrm{X}_{2}^{2} \\
& -0.00004 \mathrm{X}_{3}^{2}-0.00001 \mathrm{X}_{1} \mathrm{X}_{2} \\
& -0.000004 \mathrm{X}_{1} \mathrm{X}_{3}-0.016 \mathrm{X}_{2} \mathrm{X}_{3}
\end{aligned}
$$

where $X_{1}$ was the sucrose concentration $(m M), X_{2}$ was the glucansucrase unit $(\mathrm{mU} / \mathrm{mL})$, and $X_{3}$ was the ellagic acid concentration $(\mathrm{mM}) \cdot \mathrm{R}^{2}$ value from this regression equation was 0.82 , which explained $82 \%$ of the variation in the response (Additional file 1: Table S2). If the $\mathrm{R}^{2}$ value is greater than 0.8 , a close correlation is considered. An adequate precision value is indicative of a signal-tonoise ratio index. If the value is higher than 4 , it indicates proper prerequisites for a good fitting model. That value of this model was 5.56, suggesting that navigation of the design space of the model was capable. The predicted value of ellagic acid glucose production was $3.47 \mathrm{mM}$ and the experimental value was $3.51 \pm 0.38 \mathrm{mM}$ with $355 \mathrm{mM}$ sucrose, $650 \mathrm{mU} / \mathrm{mL}$ glucansucrase, and $12.5 \mathrm{mM}$ ellagic acid, showing similarities between the predicted value and the observed value of ellagic acid glucoside produc-

\begin{tabular}{|c|c|c|c|c|c|}
\hline \multirow[t]{2}{*}{ Run no. } & \multicolumn{3}{|c|}{ Coded levels } & \multicolumn{2}{|c|}{$\begin{array}{l}\text { Ellagic acid glucoside } \\
\text { synthesis (mM) }\end{array}$} \\
\hline & $x_{1}$ & $x_{2}$ & $x_{3}$ & Actual & Predicted \\
\hline 1 & 150 & 300 & 5.0 & 0.97 & 0.47 \\
\hline 2 & 560 & 300 & 5.0 & 0.75 & 0.36 \\
\hline 3 & 150 & 1000 & 5.0 & 2.88 & 2.27 \\
\hline 4 & 560 & 1000 & 5.0 & 2.70 & 2.30 \\
\hline 5 & 150 & 300 & 20.0 & 1.45 & 0.82 \\
\hline 6 & 560 & 300 & 20.0 & 1.08 & 0.67 \\
\hline 7 & 150 & 1000 & 20.0 & 2.76 & 2.12 \\
\hline 8 & 560 & 1000 & 20.0 & 2.62 & 2.10 \\
\hline 9 & 10.2 & 650 & 12.5 & 0.72 & 1.65 \\
\hline 10 & 699.8 & 650 & 12.5 & 1.02 & 1.55 \\
\hline 11 & 355 & 61.4 & 12.5 & 0.01 & 0.66 \\
\hline 12 & 355 & 1238.6 & 12.5 & 2.58 & 3.38 \\
\hline 13 & 355 & 650 & 0.1 & 0.21 & 0.83 \\
\hline 14 & 355 & 650 & 25.1 & 0.13 & 0.96 \\
\hline 15 & 355 & 650 & 12.5 & 4.09 & 3.47 \\
\hline 16 & 355 & 650 & 12.5 & 3.10 & 3.47 \\
\hline 17 & 355 & 650 & 12.5 & 3.49 & 3.47 \\
\hline 18 & 355 & 650 & 12.5 & 3.27 & 3.47 \\
\hline 19 & 355 & 650 & 12.5 & 3.83 & 3.47 \\
\hline 20 & 355 & 650 & 12.5 & 3.27 & 3.47 \\
\hline
\end{tabular}
tion. The optimum yield for ellagic acid glucoside was
Table 1 Central composite design matrix for the experiment and predicted responses for the synthesis of ellagic acid glucoside

$\mathrm{Y}=-4.630+0.011 \mathrm{X}_{1}+0.008 \mathrm{X}_{2}+0.443 \mathrm{X}_{3}+0.0000004 \mathrm{X}_{1}^{2}-0.000008 \mathrm{X}_{2}^{2}$ $-0.00004 X_{3}^{2}-0.00001 X_{1} X_{2}-0.000004 X_{1} X_{3}-0.016 X_{2} X_{3}$ 

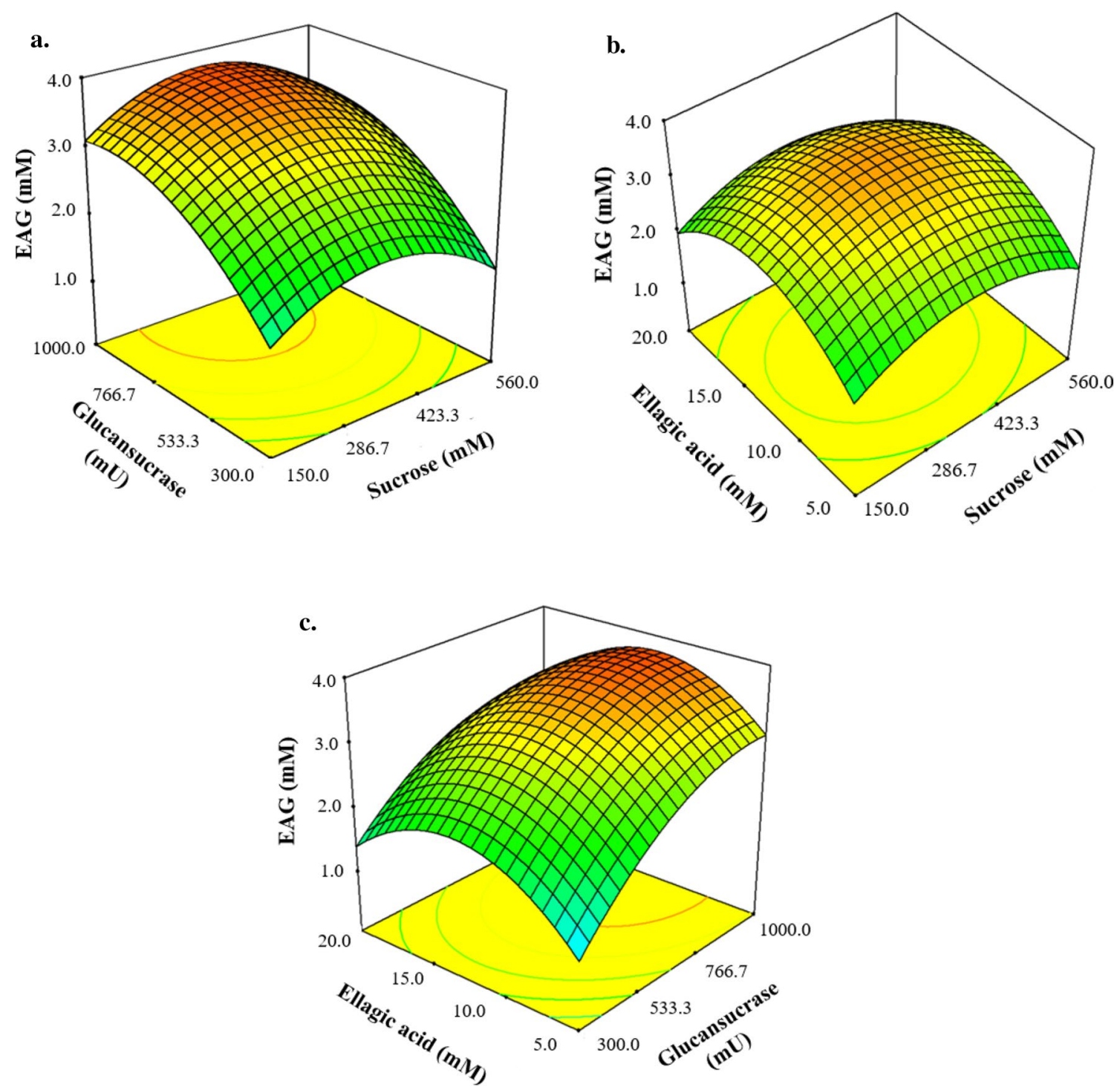

Fig. 2 Response surface and contour plots of ellagic acid glucoside (EAG) production. Mutual interactions between glucansucrase and sucrose (a), between ellagic acid and sucrose (b), and between ellagic acid and glucansucrase (c) are shown. The synthesis of ellagic acid glucoside was optimized using different concentrations of glucansucrase from L. mesenteroides (61-1239 mU/mL), sucrose (10-700), and ellagic acid (0.1-25.1 mM)

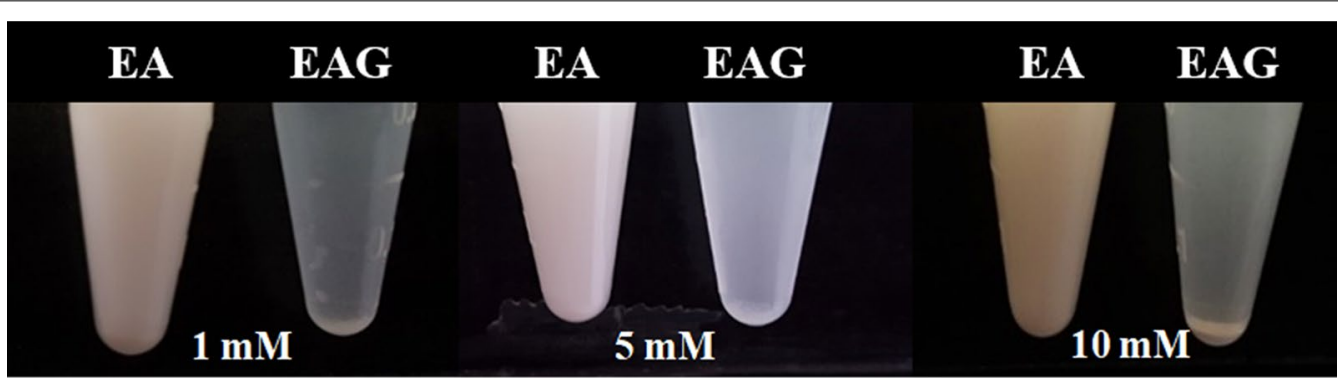

Fig. 3 Water solubility comparison of ellagic acid (EA) and ellagic acid glucoside (EAG) at concentrations of 1, 5, and $10 \mathrm{mM}$ 


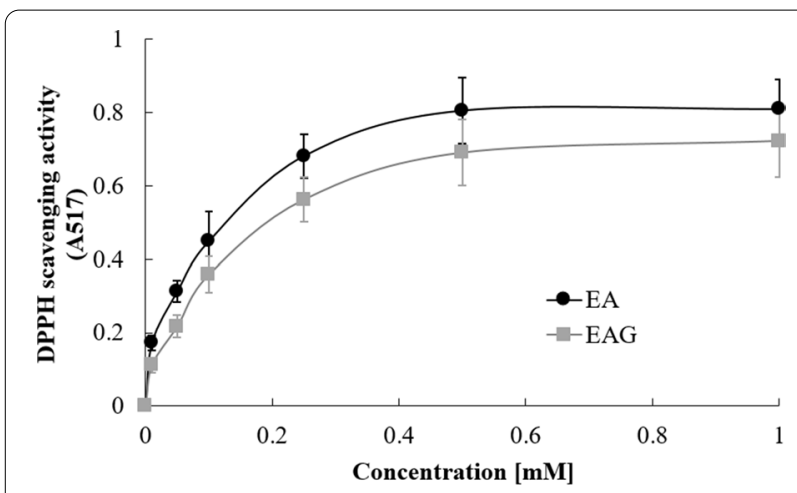

Fig. 4 DPPH radical-scavenging activities of EA and EAG at concentrations of $0,0.01 .0 .05,0.1,0.25,0.5$, and $1.0 \mathrm{mM}$. The reaction was monitored at $517 \mathrm{~nm}$. Data are reported as mean \pm SD of three separate experiments

$3.47 \mathrm{mM}$ or $69 \%$ by reacting $300 \mathrm{mU} / \mathrm{mL}$ glucansucrase with $5 \mathrm{mM}$ ellagic acid and $150 \mathrm{mM}$ sucrose (Fig. 2).

\section{Enhancement of solubility in water}

Ellagic acid is hardly soluble in water, although it could be dissolved up to $5 \mathrm{mM}$ after transglycosylation (Fig. 3). Such enhancement of its water solubility indicates that attached glucosyl residue could positively affect its water solubility. These results are consistent with those of our previous studies demonstrating a higher solubility of caffeic acid or quercetin after glycosylation as compared to a nonglycosylated state (Nam et al. 2017a; Moon et al 2007a).

\section{Antioxidant activity of ellagic acid}

Antioxidant activities of ellagic acid and its glucoside were determined by DPPH scavenging assay. Results are shown in Fig. 4. $\mathrm{IC}_{50}$ value of ellagic acid glucoside was $0.27 \mathrm{mM}$, which was higher than that of ellagic acid $\left(\mathrm{IC}_{50}=0.18 \mathrm{mM}\right)$. Because a lower $\mathrm{IC}_{50}$ value means a better antioxidant, transglycosylation of ellagic acid could not improve its antioxidant activity. These results indicate that the binding of glucose or sugar moiety can reduce the antioxidant capacity of compounds, consistent with our previous studies (Nam et al. 2017a, b).

\section{Brain cell protective, anti-stress, and anti-dementia effects of ellagic acid}

The inhibition of SH-SY5Y brain nerve cells growth by ellagic acid and its glucoside at the concentration range of 1.5-200 $\mu \mathrm{M}$ was evaluated. They did not inhibit cell growth with over $85 \%$ cell viability of the cells (Additional file 1: Fig. S1). The experiment of brain cell protective effect of ellagic acid glucoside using SH-SY5Y brain nerve cells showed $2-58 \%$ higher cell viability than the effect of ellagic acid at the same concentration. Compared with $10 \mu \mathrm{M}$ theanine well-known to have brain-protective effect, $50 \mu \mathrm{M}$ ellagic acid glucoside showed about $80 \%$ of cell viability. In addition, the cell viability of $100 \mu \mathrm{M}$ ellagic acid was not statistically significant with that of $10 \mu \mathrm{M}$ theanine (Fig. 5a, b).

Cortisol content in cells treated with ellagic acid glucoside at $10 \mu \mathrm{M}$ was $7.7 \mathrm{ng} / \mathrm{mL}$, which was lower than that $(20.2 \mathrm{ng} / \mathrm{mL})$ in cells treated with ellagic acid at $10 \mu \mathrm{M}$. This result indicates that ellagic acid glucoside has greater anti-stress effect than ellagic acid (Fig. 5c).

Furthermore, the inhibition rate for AChE enzymes known to degrade acetylcholine, a neurotransmitter, was measured to find out the anti-dementia effect. Compared to $10 \mu \mathrm{M}$ tacrine commonly used to treat degenerative brain diseases such as dementia by inhibiting AChE enzyme, ellagic acid glucoside showed 32\% of AChE inhibition rate at a concentration of $50 \mu \mathrm{M}$. This rate was four times higher than that with ellagic acid at the same concentration (Fig. 5d).

\section{Discussion}

Ellagic acid glucoside was synthesized by an acceptor reaction of glucansucrase with ellagic acid and sucrose via $\alpha$-glycosidic linkage. A previous study has shown that the attachment of xylose and rhamnose to ellagic acid formed by chemical synthesis can increase the inhibition activity of biofilm formed by bacteria (Fontaine et al. 2017). Meanwhile, our studies derived an attachment of glucose to ellagic acid using only edible enzymes and sucrose. Therefore, it can be used in the processed food or cosmetics industry. Many previous studies have used glucansucrase obtained from L. mesenteroides to transfer glucose or sugar moiety to functional compounds. For example, caffeic acid-3-O- $\alpha$-glucopyranoside was synthesized by binding glucose to caffeic acid using the enzyme (Nam et al. 2017a). Another study also showed that $44 \%$ of luteolin was converted to luteolin glucosides, of which $17 \%$ were luteolin-4'-O- $\alpha$-D-glucopyranoside and $27 \%$ were luteolin-3'-O- $\alpha$-D-glucopyranoside (Bertrand et al. 2006). Whether the glucose moiety could bind to the hydroxyl group of carbon $3^{\prime}$ or $4^{\prime}$ of ellagic acid can be predicted by looking at the structure of okicamelliaside. Okicamelliaside is a natural substance in which glucose is bound to carbon $4^{\prime}$ of 3,4-dioxoloellagic acid. It is found in camellia leaves (Onodera et al. 2010).

Previous studies have indicated that the binding of glucose or sugar moiety to a substance can decrease its antioxidant effect. For example, the attachment of fructose to hydroquinone can decrease its antioxidants activity (Seo et al. 2009). 
a.

Control

Glutamate

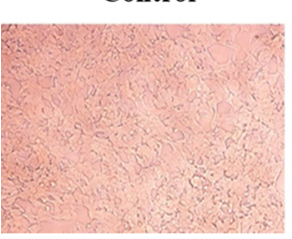

$(100 \mathrm{mM})$

EA $(50 \mu \mathrm{M})$

EAG $(50 \mu \mathrm{M})$
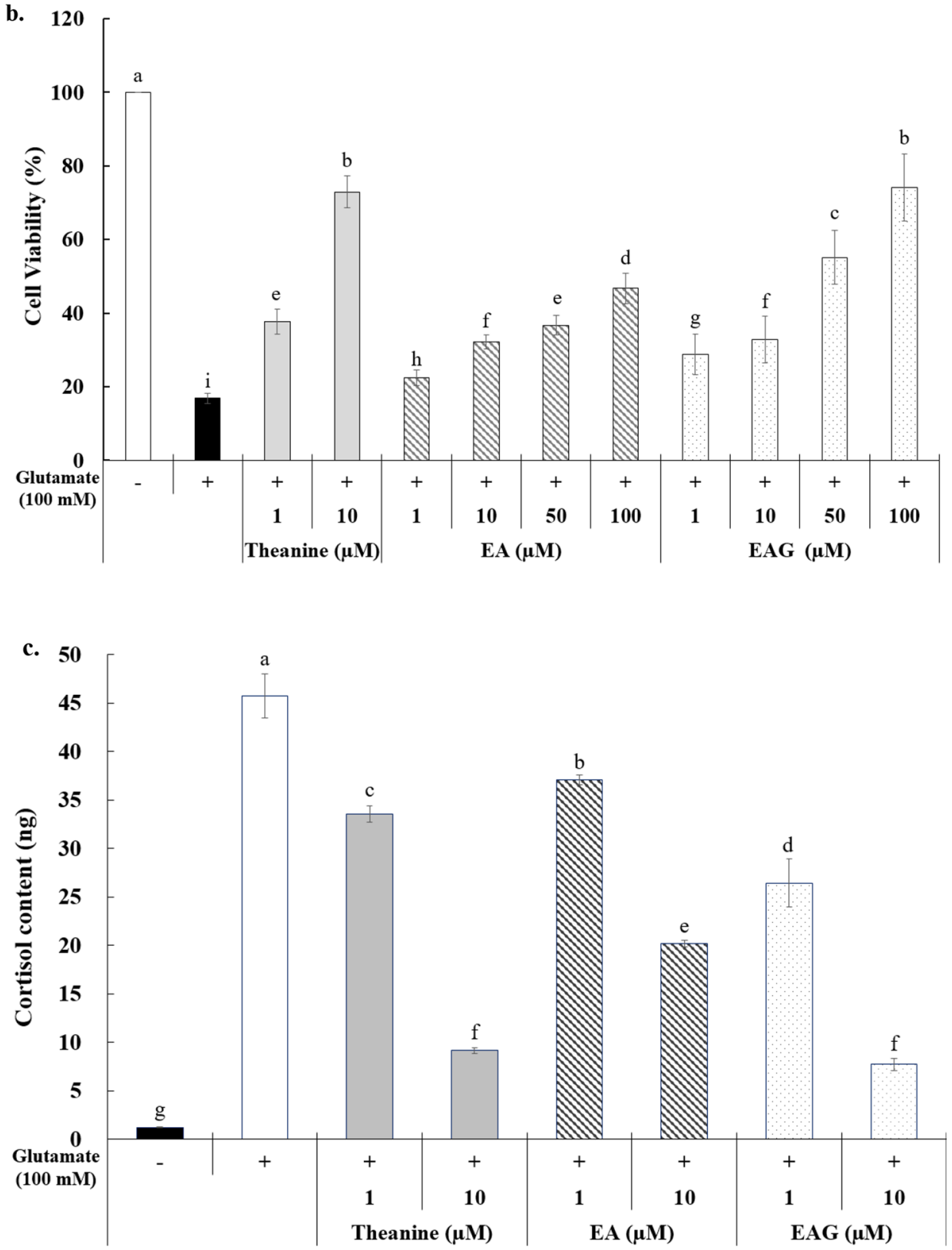

Fig. 5 Functional evaluation of EA and EAG using SH-SY5Y cells. The morphological photograph showing that EA and EAG are pretreated to prevent cell damage from glutamate treatment (a). Cell viability according to treatment with 1-100 $\mu \mathrm{M}$ of EA or EAG compared with only buffer treatment. As positive controls, 1 and $10 \mu \mathrm{M}$ of theanine were treated (b). Cortisol content in the cells treated with 1 or $10 \mu \mathrm{M}$ theanine, EA, or EAG before treatment of glutamate (c). Inhibition rate of AChE enzyme after treatment with $100 \mathrm{mM}$ glutamate followed by treatment with $10 \mu \mathrm{M}$ tacrine, 50 or $100 \mu \mathrm{M}$ of EA or EAG (d). Mean with same letter in each column are not significantly different by Duncan's multiple range test $(p<0.05)$ 


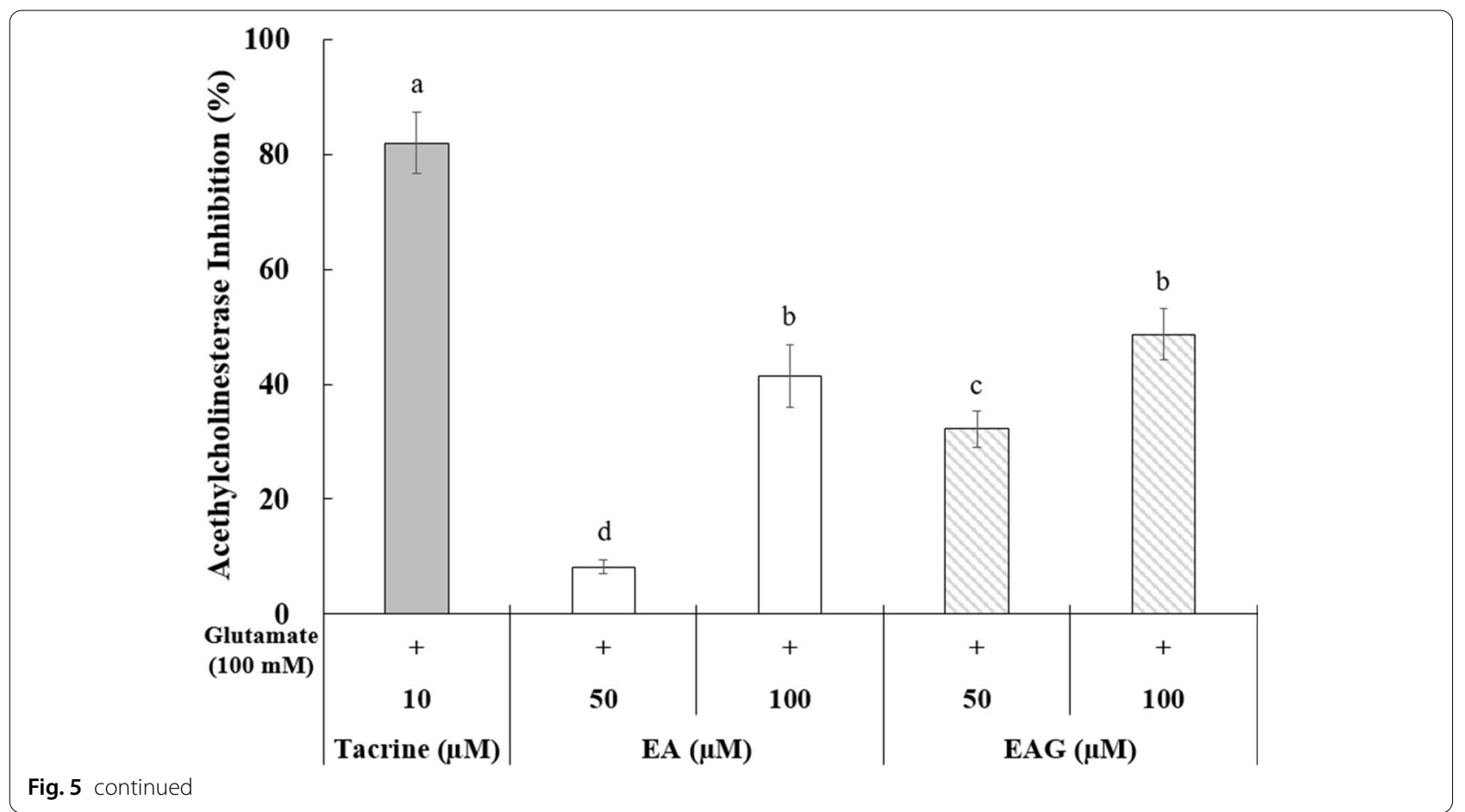

Also, gallic acid glucoside shows sevenfold lower antioxidants activity than gallic acid (Nam et al. 2017a, b).

Treatment with glutamate can cause damage to SHSY5Y cells, including a decrease of cell viability, an increase of lactate dehydrogenase (LDH) release, and alterations of morphological structures (Sun et al. 2010). Theanine, a well-known brain-protectant compound, was used as a positive control in the present study. According to a previous study, pretreatment of cells with L-theanine can significantly block rotenone- or dieldrin-induced nuclear damage (Cho et al. 2008). Another study has revealed that ellagic acid $(0.01-10 \mu \mathrm{M})$ can significantly increase cell proliferation and GSH level while decreasing levels of reactive oxygen species (ROS), MDA, TNF$\alpha, \beta$-galctosidase, and advanced glycation end products following D-galactose induced aging (Rahimi et al. 2018).

Cortisol as a steroid is widely known as the body's stress hormone. If human body is exposed to an internal or external stressor, cortisol is released from the adrenal cortex. It allows the body to continue to stay on high alert (Thau and Sharma 2020). In a previous study, saliva cortisol level in overweight people is inhibited by $22.7 \%$ after 12-week of ellagic acid treatment (Liu et al. 2018). In the present study, cells treated with ellagic acid glucoside showed higher cortisol inhibition than those treated with ellagic acid at the same concentration.

Inhibition of cholinesterases is important in order to fight against Alzheimer's disease. A previous study has shown that ellagic acid has a greater AChE inhibitory activity than other natural products such as quercetin, rutin, and chlorogenic acid (Neagu et al. 2015). The present study showed that ellagic acid glucoside had higher AChE inhibition effect than its precursor compound. Thus, ellagic acid glucoside could be used as a functional component for brain protection.

\section{Abbreviations}

EA: Ellagic acid; EAG: Ellagic acid glucoside; LC-MS/MS: Liquid chromatography tandem mass spectrometry; AChE: Acetylcholinesterase; MTT: 3-(4,5-Dimethylthiazol-2-yl)-2,5-diphenyl-tetrazolium bromide; DPPH: 1,1-Diphenyl-2-picrylhydrazyl; TLC: Thin-layer chromatography; HPLC: High-pressure liquid chromatography; PDA: Photodiode array detector; RSM: Response surface methodology; CCD: Central composite design; MAb: Monoclonal antibody.

\section{Supplementary Information}

The online version contains supplementary material available at https://doi. org/10.1186/s13568-021-01265-x.

Additional file 1: Figure S1. MTT assay was performed to evaluate the potential cytotoxic activity. SH-SY5Y cells were treated with different concentrations of ellagic acid or ellagic acid glucoside $(1.5-200 \mu \mathrm{M})$. Results are presented as mean \pm standard deviation of triplicate repeats. $*$, $* *$ : Significantly different from the control group at $p<0.05$ and $p<0.01$, respectively. Table S1. Independent variables, levels, and experimental codes used in response surface methodology (RSM). Table S2. ANOVA for RSM parameters fitted to second-order polynomial equations.

\section{Acknowledgements}

This study was supported by grants (NRF-2016R1D1A1B03936148; NRF2020R1I1A1A01074322) of the Basic Science Research Program through the National Research Foundation (NRF) funded by the Ministry of Education, 
Republic of Korea. Thank you to professor Doman Kim of Seoul National University for providing the strain of L. mesenteroides B-512 FMCM (KCCM 11728P).

\section{Authors' contributions}

All authors were involved in the design of this study. Data collection was mainly done by $\mathrm{HY}$ and $\mathrm{HJ}$. Data analysis and data interpretation were done by J-YC and IKH. Manuscript writing and preparation of figures were completed by S-HN, K-YY and HY. Important revisions were made by S-HN and K-YY. Approval of the final draft was obtained from all authors. All authors read and approved the final manuscript.

\section{Funding}

This study was supported by grants (NRF-2016R1D1A1B03936148; NRF2020R111A1A01074322) of the Basic Science Research Program through the National Research Foundation (NRF) funded by the Ministry of Education, Republic of Korea.

\section{Availability of data and materials}

Not applicable.

\section{Declarations}

Ethics approval and consent to participate

Not applicable.

\section{Consent for publication}

Not applicable.

\section{Competing interests}

The authors have no competing interests relevant to this study to disclose.

\section{Author details}

${ }^{1}$ Institute of Agricultural Science and Technology, Chonnam National University, Gwangju 61186, South Korea. ${ }^{2}$ Department of Applied Biology Graduate School, Chonnam National University, Gwangju 61186, South Korea. ${ }^{3}$ Division of Food Technology \& Biotechnology, Chonnam National University, Gwangju 61186, South Korea. ${ }^{4}$ Kolmar Korea R\&D Center, 61, Heolleung-ro 8-gil, Seocho-gu, Seoul 06800, Republic of Korea.

Received: 14 May 2021 Accepted: 3 July 2021

Published online: 21 July 2021

\section{References}

Bertrand A, Morel S, Lefoulon F, Rolland Y, Monsan P, Remaud-Simeon M (2006) Leuconostoc mesenteroides glucansucrase synthesis of flavonoid glucosides by acceptor reactions in aqueous-organic solvents. Carbohydr Res 341(7):855-863127

Cho HS, Kim S, Lee SY, Park JA, Kim SJ, Chun HS (2008) Protective effect of the green tea component, L-theanine on environmental toxins-induced neuronal cell death. Neurotoxicology 29(4):656-662

Farbood Y, Sarkaki A, Dianat M, Khodadadi A, Haddad MK, Mashhadizadeh S (2015) Ellagic acid prevents cognitive and hippocampal long-term potentiation deficits and brain inflammation in rat with traumatic brain injury. Life Sci 124:120-127

Fontaine BM, Nelson K, Lyles JT, Jariwala PB, García-Rodriguez JM, Quave CL, Weinert EE (2017) Identification of ellagic acid rhamnoside as a bioactive component of a complex botanical extract with anti-biofilm activity. Front Microbiol 8:496

Kasai K, Yoshimura M, Koga T, Arii M, Kawasaki S (2006) Effects of oral administration of ellagic acid-rich pomegranate extract on ultraviolet-induced pigmentation in the human skin. J Nutr Sci Vitaminol 52(5):383-388

Khuri Al, Mukhopadhyay S (2010) Response surface methodology. Wiley Interdiscip Rev Comput Stat 2(2):128-149

Liu Y, Yu S, Wang F, Yu H, Li X, Dong W, Lin R, Liu Q (2018) Chronic administration of ellagic acid improved the cognition in middle-aged overweight men. Appl Physiol Nutr Metab 43(3):266-273
Moon YH, Lee JH, Ahn JS, Nam SH, Oh DK, Park DH, Chung HJ, Kang S, Day DF, Kim D (2006) Synthesis, structure analyses, and characterization of novel epigallocatechin gallate (EGCG) glycosides using the glucansucrase from Leuconostoc mesenteroides B-1299CB. J Agric Food Chem 54(4):1230-1237

Moon YH, Lee JH, Jhon DY, Jun WJ, Kang SS, Sim J, Choi H, Moon JH, Kim D (2007a) Synthesis and characterization of novel quercetin- $a-D-$ glucopyranosides using glucansucrase from Leuconostoc mesenteroides. Enzyme Microb Technol 40(5):1124-1129

Moon YH, Nam SH, Kang J, Kim YM, Lee JH, Kang HK, Breton V, Jun WJ, Park KD, Kimura A (2007b) Enzymatic synthesis and characterization of arbutin glucosides using glucansucrase from Leuconostoc mesenteroides B-1299CB. Appl Microbiol Biotechnol 77(3):559-567

Nam SH, Kim YM, Walsh MK, Wee YJ, Yang KY, Ko JA, Han S, Thanh Hanh Nguyen T, Kim JY, Kim D (2017a) Synthesis and functional characterization of caffeic acid glucoside using Leuconostoc mesenteroides dextransucrase. J Agric Food Chem 65(13):2743-2750

Nam SH, Park J, Jun W, Kim D, Ko JA, Abd El Aty A, Choi JY, Kim DI, Yang KY (2017b) Transglycosylation of gallic acid by using Leuconostoc glucansucrase and its characterization as a functional cosmetic agent. AMB Express 7(1):1-10

Neagu E, Paun G, Albu C, Radu GL (2015) Assessment of acetylcholinesterase and tyrosinase inhibitory and antioxidant activity of Alchemilla vulgaris and Filipendula ulmaria extracts. J Taiwan Inst Chem Eng 52:1-6

Onodera KI, Tsuha K, Yasumoto-Hirose M, Tsuha K, Hanashiro K, Naoki H, Yasumoto T (2010) Okicamelliaside, an extraordinarily potent anti-degranulation glucoside isolated from leaves of Camellia japonica. Biosci Biotechnol Biochem 74(12):2532-2534

Priyadarsini Kl, Khopde SM, Kumar SS, Mohan H (2002) Free radical studies of ellagic acid, a natural phenolic antioxidant. J Agric Food Chem 50(7):2200-2206

Rahimi VB, Askari VR, Mousavi SH (2018) Ellagic acid reveals promising antiaging effects against $\mathrm{D}$-galactose-induced aging on human neuroblastoma cell line, SH-SY5Y: a mechanistic study. Biomed Pharmacother 108:1712-1724

Robyt JF, Yoon SH, Mukerjea R (2008) Dextransucrase and the mechanism for dextran biosynthesis. Carbohydr Res 343(18):3039-3048

Seo ES, Kang J, Lee JH, Kim GE, Kim GJ, Kim D (2009) Synthesis and characterization of hydroquinone glucoside using Leuconostoc mesenteroides dextransucrase. Enzyme Microb Technol 45(5):355-360

Sun ZW, Zhang L, Zhu SJ, Chen WC, Mei B (2010) Excitotoxicity effects of glutamate on human neuroblastoma SH-SY5Y cells via oxidative damage. Neurosci Bull 26(1):8-16

Thau L, Sharma S (2020) Physiology, cortisol. StatPearls

Yoshimura M, Watanabe Y, Kasai K, Yamakoshi J, Koga T (2005) Inhibitory effect of an ellagic acid-rich pomegranate extract on tyrosinase activity and ultraviolet-induced pigmentation. Biosci Biotechnol Biochem 69(12):2368-2373

\section{Publisher's Note}

Springer Nature remains neutral with regard to jurisdictional claims in published maps and institutional affiliations.

\section{Submit your manuscript to a SpringerOpen ${ }^{\circ}$ journal and benefit from:}

- Convenient online submission

- Rigorous peer review

- Open access: articles freely available online

- High visibility within the field

- Retaining the copyright to your article

Submit your next manuscript at $\boldsymbol{\nabla}$ springeropen.com 